\title{
Relação proteína:carboidrato no desempenho e no metabolismo de híbridos de Pseudoplatystoma fasciatum (fêmea) X Leiarius marmoratus (macho)
}

\author{
[Evaluation of protein:carbohydrate ratio in the diet of hybrids of Pseudoplatystoma fasciatum \\ (female) X Leiarius marmoratus (male)] \\ S.A. Souza $a^{1}$, R.C. Souza ${ }^{1}$, D.F.B. Campeche ${ }^{2}$, R.M.L. Campos $^{1}$, J.F.B. Melo ${ }^{1 *}$ \\ ${ }^{1}$ Universidade Federal do Vale do São Francisco - Univasf - Petrolina, PE \\ ${ }^{2}$ Empresa Brasileira de Pesquisa Agropecuária - Embrapa Semiárido - Petrolina, PE
}

\begin{abstract}
RESUMO
Objetivou-se, neste trabalho, determinar a melhor relação entre proteína e carboidrato na dieta do híbrido carnívoro Pseudoplatystoma fasciatum e Leiarius marmoratus. Utilizou-se um sistema fechado de recirculação de água, composto de 12 caixas de 500L e biofiltro. Foram utilizados 144 juvenis (12/caixa) com peso médio inicial de $12,63 \pm 2,52 \mathrm{~g}$ e comprimento total de $12,34 \pm 2,06 \mathrm{~cm}$ durante 50 dias. Os peixes receberam quatro dietas contendo diferentes relações proteína:carboidrato $(1,24 ; 0,84 ; 0,56$ e 0,33$)$. A relação proteína:carboidrato influenciou o desempenho e os parâmetros metabólicos dos animais. A melhor relação proteína:carboidrato para o desempenho foi 0,84 . Os resultados metabólicos demonstraram mobilização de nutrientes para manutenção de glicemia e do crescimento. A relação proteína:carboidrato de 0,84 foi a mais indicada para o híbrido.
\end{abstract}

Palavras-chave: nutrição, peixes, híbridos, proteína:carboidrato

\begin{abstract}
The purpose of this study was to determine the best protein:carbohydrate ratio in this hybrid's diet. A water recirculation closed system was used, composed of twelve tanks with 500L each. 144 juveniles $(12 /$ tank) with initial weight of $12.63 \pm 2.52 \mathrm{~g}$ and total length of $12.34 \pm 2.06 \mathrm{~cm}$ were distributed. The experiment lasted for 50 days and the fingerlings were feed four diets containing different protein:carbohydrate ratios $(1.24 ; 0.84 ; 0.56$ and 0.33$)$. The protein:carbohydrate ratio influenced performance. The 0.84 ratio promoted better weight gain, smaller apparent feed conversion, great feed intake and largest daily specific growth rate. In short, the 0.84 protein:carbohydrate ratio is most indicated for this hybrid. The results demonstrated metabolic mobilization of nutrients for maintenance of glucose and growth. The 0.84 protein: carbohydrate ratio was recommended for the hybrid.
\end{abstract}

Keywords: nutrition, fish, hybrids, protein/carbohydrate

\section{INTRODUÇÃO}

$\mathrm{Na}$ aquicultura, o custo com alimentação representa, em média, $52,19 \%$ do total do custo de produção (Andrade et al., 2005), e a proteína constitui o item mais oneroso da dieta para peixes (Botaro et al., 2007). Os peixes usam a maior parte dos aminoácidos obtidos na dieta na degradação muscular para a manutenção de suas necessidades energéticas (Viaplana-Marín et al.,

Recebido em 11 de julho de 2012

Aceito em 5 de setembro de 2013

*Autor para correspondência (corresponding author)

E-mail: melojfb@yahoo.com.br
2006), e os excedentes não são estocados, mas sim degradados e eliminados para o ambiente aquático como compostos nitrogenados que se tornam substrato para o crescimento de microrganismos aquáticos, levando a uma possível eutrofização da água de cultivo (Buttle et al., 1995; Fernández et al., 2007).

O carboidrato constitui a fonte energética de menor custo na alimentação de peixes (Silveira et al., 2009). A substituição parcial de proteína 
por carboidrato em dietas de peixes poupa o uso da proteína na produção de energia, desde que em níveis adequados (Hemre et al., 2002; Fernández et al., 2007). O uso de fontes alternativas de carboidratos tem apresentado respostas ao desempenho e nos processos de digestão dos peixes (Melo et al., 2012; Melo et al., 2012a).

O peixe utilizado neste experimento foi o híbrido de Pseudoplatystoma fasciatum e Leiarius marmoratus. A utilização de vários híbridos de espécies neotropicais é uma prática comum entre os produtores brasileiros (Hashimoto, 2008) e tem objetivado a transferência de características desejáveis entre diferentes espécies. A hibridação de Siluriformes da família Pimelodidae tem despertado o interesse em criadores, tanto para produção de peixes ornamentais como para consumo (Kossowski, 2001). Segundo Mateo e Rojas (2005), o híbrido de $P$. fasciatum e $L$. marmoratus demonstrou grande potencial para cultivo, possuindo pequena incompatibilidade genética, semelhança numérica e morfológica dos cromossomos entre as espécies progenitoras, além de menor taxa de canibalismo durante a fase de pós-larva e alevino, boa aceitação de rações e alimentos concentrados e aspectos fenotípicos comercialmente atrativos (Mateo et al., 2008). Embora as características zootécnicas desse peixe sejam de interesse dos produtores, ainda são escassos os trabalhos sobre crescimento em condições intensivas (Faria et al., 2011). Estes autores obtiveram, em testes de densidades para esse híbrido, o ganho de $1,1 \mathrm{~kg}$ de peso vivo em sete meses de cultivo. Em relação aos progenitores desse híbrido, o $P$. fasciatum é considerado nobre devido às qualidades de filés com cor clara, textura firme, sabor pouco acentuado e espinhos ausentes (Frascá-Scorvo et al., 2004). O L. marmoratus apresenta como características adaptação no confinamento, consumo de dietas secas e bom crescimento nos estágios iniciais de vida (CruzCasallas et al., 2008). Portanto, o híbrido como alternativa para a produção em piscicultura intensiva pode reunir as características dos grupos parentais com melhor desempenho.
O objetivo do presente trabalho foi avaliar a melhor relação entre a proteína e o carboidrato usado na dieta do híbrido de $P$. fasciatum e $L$. marmoratus.

\section{MATERIAL E MÉTODOS}

O experimento foi conduzido no Laboratório de Aquicultura da Universidade Federal do Vale do São Francisco. Foram utilizados 12 tanques de 500L, montados em sistema fechado de recirculação de água com biofiltro. Foram estocados 12 juvenis/tanque do híbrido de $P$. fasciatum (fêmea) e L. marmoratus (macho), obtidos por reprodução induzida. $\mathrm{O}$ peso médio inicial era de $12,63 \pm 2,52 \mathrm{~g}$, e o comprimento total médio inicial de $12,34 \pm 2.06 \mathrm{~cm}$. O período experimental foi de 50 dias. Os peixes foram alimentados com quatro dietas experimentais contendo diferentes relações de proteína bruta e carboidrato (PB:CHO), nas razões de $0,33,0,51$; 0,84 e 1,24 (Tab. 1).

As dietas foram confeccionadas, após pesagem e homogeneização dos ingredientes, com adição de água e, posteriormente, foram peletizadas. As rações foram secas em estufa de ventilação forçada a $45^{\circ} \mathrm{C}$, durante um período de 24 horas, e mantidas sob refrigeração a $5^{\circ} \mathrm{C}$ (adaptado de Furuya et al., 2001). Diariamente eram ofertadas na proporção de $8 \%$ da biomassa, duas vezes ao dia (às oito e às 17 horas). As caixas, diariamente, eram sifonadas duas vezes para limpeza, e logo se fazia a reposição de $30 \%$ do volume da água, bem como se mediam o $\mathrm{pH}$, a temperatura e o oxigênio dissolvido duas vezes ao dia. $\mathrm{O}$ desempenho dos animais foi avaliado com base nos seguintes parâmetros: peso médio final (PMF), ganho de peso médio diário (GPMD), ganho de peso médio (GPM), comprimento total (CT), rendimento de carcaça (RC), consumo total de ração aparente (CTRA), conversão alimentar aparente (CAA), determinada pela razão entre a quantidade de alimento oferecido e o ganho de peso médio (GPM), e taxa de crescimento específico diário (TCE), definida pela equação: TCE $\left(\% \cdot \operatorname{dia}^{-1}\right)=$ [(ln peso final $(\mathrm{g})$ - $\ln$ peso inicial).100.tempo $\left.(\operatorname{dias})^{-1}\right]$. 
Relação proteína:carboidrato...

Tabela 1. Composição percentual e análise bromatológica das dietas utilizadas na alimentação de juvenis de híbridos de Pseudoplatystoma fasciatum (fêmea) X Leiarius marmoratus (macho)

\begin{tabular}{lcccc}
\hline \multirow{2}{*}{ Ingredientes } & \multicolumn{3}{c}{ Relações PB:CHO } & 0,33 \\
\cline { 2 - 5 } & 1,24 & 0,84 & 0,51 & 26,6 \\
\hline Farinha de peixe & 64,1 & 51,6 & 39,1 & 2,5 \\
Farelo de soja & 10 & 7,5 & 5 & 60 \\
Farinha de milho & 15 & 30 & 45 & 8 \\
Óleo de soja & 8 & 8 & 8 & 2 \\
Premix mineral e vitamínico & 2 & 2 & 2 & 0,05 \\
Vit C $^{2}$ & 0,05 & 0,05 & 0,05 & 0,01 \\
BHT $^{3}$ & 0,01 & 0,01 & 0,01 & 0,84 \\
Fosfato bicálcico & 0,84 & 0,84 & 0,84 & 100 \\
Total & 100 & 100 & 100 & 20,84 \\
\hline & Composição bromatológica & 62,83 \\
\hline PB (\%) & 39,52 & 34,06 & 27,03 & 5139 \\
ENN (\%) & 31,90 & 40,64 & 52,55 & 8,02 \\
EB (Kcal/kg) & 5263 & 5279 & 5190 & 3,04 \\
EE (\%) & 9,81 & 9,05 & 8,88 & 09,27 \\
FB (\%) & 2,95 & 2,90 & 2,98 & 90,73 \\
MM (\%) & 18,82 & 16,35 & 12,56 & 90,75 \\
MO (\%) & 81,18 & 83,65 & 87,44 & 93,19 \\
MS (\%) & 94,21 & 93,64 & & \\
\hline
\end{tabular}

${ }^{\mathrm{T}}$ Premix min. e vit. (Supremais, Campinas-SP): composição por quilo de produto: Vit. A $=1.200 .000$ UI; vit. D3 = 200.000 UI; vit. $\mathrm{E}=12.000 \mathrm{mg}$; vit. $\mathrm{K} 3=2400 \mathrm{mg}$; vit. $\mathrm{B} 1=4800 \mathrm{mg}$; vit. $\mathrm{B} 2=4800 \mathrm{mg}$; vit. $\mathrm{B} 6=4000 \mathrm{mg}$; vit. $\mathrm{B} 12=4800 \mu \mathrm{g}$; ác. fólico $=1200 \mathrm{mg}$; pantotenato de cálcio $=12.000 \mathrm{mg}$; vit. $\mathrm{C}=48.000 \mathrm{mg}$; biotina $=48 \mathrm{mg}$; colina $=65.000 \mathrm{mg}$; ácido nicotínico $=24.000 \mathrm{mg} ; \mathrm{Fe}=10.000 \mathrm{mg} ; \mathrm{Cu}=600 \mathrm{mg} ; \mathrm{Mn}=4000 \mathrm{mg} ; \mathrm{Zn}=6000 \mathrm{mg} ; \mathrm{I}=20 \mathrm{mg} ; \mathrm{Co}=2 \mathrm{mg}$ e Se $=20 \mathrm{mg}$.

${ }^{2}$ Vit. C (Basf, São Paulo-SP): sal cálcico 2-monofosfato de ácido ascórbico, $42 \%$ de princípio ativo.

${ }^{3}$ Butil-hidroxitolueno.

${ }^{4} \mathrm{MS}$ - Matéria seca; EE - extrato estéreo; PB - proteína bruta; MO - matéria orgânica; FB - fibra bruta; CHO - carboidrato; LP lipídios; $\mathrm{PB}: \mathrm{CHO}$ - proporção proteína bruta/carboidrato; EB - energia bruta; MM - matéria mineral. ENN - Extrativo não nitrogenado.

Ao término do período experimental, foram amostrados aleatoriamente 10 animais de cada tratamento, dos quais foi coletado sangue, por meio de punção da veia caudal, para obtenção de plasma, no qual foram quantificadas as concentrações de glicose (GLIC), colesterol (COL) e proteínas totais (PTN). Logo após a insensibilização em água com gelo, os peixes foram eutanasiados para coleta do fígado usado na determinação da atividade da enzima aspartato aminotransferase (AST) e das concentrações de glicogênio (GLIG). Todos os parâmetros metabólicos foram analisados por meio de kit comercial (Labtest Ref. 85, 76, 99, 109). As determinações de glicogênio foram realizadas conforme técnica descrita por Bidinotto et al. (1997).

As dietas foram confeccionadas, após pesagem e homogeneização dos ingredientes, com adição de água e, posteriormente, foram peletizadas. As rações foram secas em estufa de ventilação forçada a $45^{\circ} \mathrm{C}$, durante um período de 24 horas, e mantidas sob refrigeração a $5^{\circ} \mathrm{C}$ (adaptado de Furuya et al., 2001). Diariamente eram ofertadas na proporção de $8 \%$ da biomassa, duas vezes ao dia (às oito e às 17 horas). As caixas, diariamente, eram sifonadas duas vezes para limpeza, e logo se fazia a reposição de $30 \%$ do volume da água, bem como se mediam o pH, a temperatura e o oxigênio dissolvido duas vezes ao dia. $\mathrm{O}$ desempenho dos animais foi avaliado com base nos seguintes parâmetros: peso médio final (PMF), ganho de peso médio diário (GPMD), ganho de peso médio (GPM), comprimento total (CT), rendimento de carcaça (RC), consumo total de ração aparente (CTRA), conversão alimentar aparente (CAA), determinada pela razão entre a quantidade de alimento oferecido e o ganho de peso médio (GPM), e taxa de crescimento específico diário (TCE), definida pela equação: TCE $\left(\% \cdot \operatorname{dia}^{-1}\right)=$ [(ln peso final $(\mathrm{g})$ - $\ln$ peso inicial).100.tempo $\left.(\operatorname{dias})^{-1}\right]$. 
Ao término do período experimental, foram amostrados aleatoriamente 10 animais de cada tratamento, dos quais foi coletado sangue, por meio de punção da veia caudal, para obtenção de plasma, no qual foram quantificadas as concentrações de glicose (GLIC), colesterol (COL) e proteínas totais (PTN). Logo após a insensibilização em água com gelo, os peixes foram eutanasiados para coleta do fígado usado na determinação da atividade da enzima aspartato aminotransferase (AST) e das concentrações de glicogênio (GLIG). Todos os parâmetros metabólicos foram analisados por meio de kit comercial (Labtest Ref. 85, 76, 99, 109). As determinações de glicogênio foram realizadas conforme técnica descrita por Bidinotto et al. (1997).

O delineamento experimental foi inteiramente ao acaso, com quatro tratamentos e três repetições. Realizou-se a análise de variância, e as médias foram comparadas pelo teste de Tukey, com nível de significância de 5\%. Foram realizadas análises de regressão dos dados por meio do programa estatístico SAS 9.1.3 (Statistical..., 2007).

\section{RESULTADOS E DISCUSSÃO}

Os valores médios dos parâmetros físicoquímicos da água foram analisados, e obtiveramse os seguintes resultados: a temperatura média da água nas caixas foi de $23^{\circ} \mathrm{C}$. A temperatura recomendada para as espécies que vivem no clima quente é de $24^{\circ} \mathrm{C}$, portanto esteve pouco abaixo da recomendada para espécies de peixes tropicais (Boyd, 1990). Os teores médios de oxigênio dissolvido na água foram de $4,8 \mathrm{mg} . \mathrm{L}^{-1}$. $\mathrm{O}$ parâmetro $\mathrm{pH}$ apresentou pouca variação, obtendo valores entre 6,5 e 6,9. O oxigênio dissolvido e o pH, durante todo o período experimental, apresentaram-se dentro dos limites recomendados para a piscicultura (Boyd, 1990; 1998).

Os dados de desempenho zootécnico do híbrido estão descritos na Tab. 2. Os resultados do peso médio (PM) inicial dos juvenis de peixes utilizados no experimento foram homogêneos, não havendo diferenças entre os tratamentos $(\mathrm{P} \geq 0,05)$. Verificou-se que a relação $\mathrm{PB}: \mathrm{CHO}$ influenciou significativamente o peso médio final dos animais $(\mathrm{P} \leq 0,05)$. Nas relações $\mathrm{PB}: \mathrm{CHO}$ de 0,84 e 1,24 os pesos foram maiores.

Tabela 2. Valores de peso médio final (PMF), ganho em peso médio diário (GPMD), conversão alimentar aparente (CAA), taxa de crescimento específico (TCE), consumo total de ração aparente (CTRA) e rendimento de carcaça (RC) de juvenis de híbridos de Pseudoplatystoma fasciatum (fêmea) versus Leiarius marmoratus (macho) submetidos a diferentes relações proteína/carboidrato (PB:CHO), alimentados por 50 dias

\begin{tabular}{ccccccc}
\hline $\begin{array}{c}\text { Tratamentos } \\
\text { Relação }\end{array}$ & $\begin{array}{c}\text { PM } \\
\text { PB } \mathrm{CHO}\end{array}$ & $\begin{array}{c}\text { GPMD } \\
(\mathrm{g} / \mathrm{dia})\end{array}$ & CAA & $\begin{array}{c}\text { TCE } \\
(\%)\end{array}$ & $\begin{array}{c}\text { CTRA } \\
(\mathrm{g})\end{array}$ & $\begin{array}{c}\text { RC } \\
(\%)\end{array}$ \\
\hline 1,24 & $28,05 \mathrm{a}$ & $0,30 \mathrm{a}$ & $4,69 \mathrm{~b}$ & $1,00 \mathrm{a}$ & $937,95 \mathrm{~b}$ & $86,93 \mathrm{a}$ \\
0,84 & $28,86 \mathrm{a}$ & $0,22 \mathrm{a}$ & $6,30 \mathrm{~b}$ & $0,90 \mathrm{ab}$ & $952,37 \mathrm{a}$ & $88,29 \mathrm{a}$ \\
0,51 & $23,74 \mathrm{ab}$ & $0,15 \mathrm{~b}$ & $11,66 \mathrm{a}$ & $0,61 \mathrm{bc}$ & $824,60 \mathrm{c}$ & $86,75 \mathrm{a}$ \\
0,33 & $20,23 \mathrm{~b}$ & $0,14 \mathrm{~b}$ & $11,40 \mathrm{a}$ & $0,50 \mathrm{c}$ & $784,73 \mathrm{~d}$ & $84,75 \mathrm{a}$ \\
$\mathrm{CV}(\%)$ & 11,63 & 28,31 & 31,85 & 18,44 & 2,02 & 4,60 \\
\hline Equação de & $\mathrm{y}=-14,80 \mathrm{x}^{2}+$ & $\mathrm{y}=0.3013 \mathrm{x}+$ & $\mathrm{y}=-$ & $\mathrm{y}=1.3953 \mathrm{x}+$ & $\mathrm{y}=-337,7 \mathrm{x}^{2}+$ & ----- \\
regressão & $27,79 \mathrm{x}+9,147$ & 0.0809 & $5.5168 \mathrm{x}+11.015$ & 0.7864 & $717,5 \mathrm{x}+571,6$ & \\
& $\mathrm{R}^{2}=0,98$ & $\mathrm{R}^{2}=0,74$ & $\mathrm{R}^{2}=0,64$ & $\mathrm{R}^{2}=0,64$ & $\mathrm{R}^{2}=0,95$ & \\
\hline
\end{tabular}

Letras iguais na coluna indicam não haver diferença significativa pelo teste Tukey $(\mathrm{P} \leq 0,05)$, entre as relações proteína:carboidrato.

O ganho em peso médio diário (GPMD) apresentou comportamento semelhante ao peso final. As melhores relações $\mathrm{PB}: \mathrm{CHO}$ foram as de 1,24 e 0,84 (Tab. 2) para GPMD, as quais apresentaram diferença significativa em relação aos demais grupos de peixes.

O efeito da proteína e dos carboidratos na dieta sobre o desempenho dos peixes já é constatado por vários autores. As concentrações desses nutrientes sobre as necessidades nutricionais variam muito entre as espécies de peixes. Fernández et al. (2007) verificaram que inclusão com $19,6 \%$ de carboidrato e $53,9 \%$ de PB promoveu melhores índices de desempenho do carnívoro Sparus aurata. Viaplana-Marín et al. (2006) verificaram que $45,2 \%$ de proteína e 
$27,8 \%$ de carboidrato para trutas-marrom produzem maior desempenho. Os híbridos estudados nesta pesquisa obtiveram os pesos médios superiores em maiores quantidades de carboidratos $(31,90$ e 40,64\%). O comprimento total final (CT) não apresentou diferença significativa $(\mathrm{P} \geq 0,05)$ durante $\mathrm{o}$ período experimental e apresentou os seguintes valores, respectivamente: 16,$48 ; 18,11 ; 15,52$ e $14,65 \mathrm{~cm}$ nas relações PB:CHO de 1,24; 0,84; 0,51 e 0,33. Observou-se que a variável $\mathrm{CT}$ não demonstra ser um bom indicador para avaliação do desenvolvimento deste animal, no período estudado. Huang e Liao (1999) relataram que, do ponto de vista econômico, o parâmetro mais importante a ser melhorado em um programa de seleção é o crescimento, o qual destaca a forma do corpo.

A conversão alimentar aparente (CAA) foi influenciada pelas relações $\mathrm{PB}: \mathrm{CHO}$ testadas (Tab. 2). Verificou-se que os tratamentos com as relações PB:CHO de 1,24 e 0,84 apresentaram os melhores índices. As proteínas e os carboidratos geralmente influenciam esta variável devido ao consumo de ração. Tais efeitos foram observados por Moreira et al. (2008) em juvenis do carnívoro Dicentrarchus labrax, por Sousa (2005) em P. corruscans e por Izel et al. (2004) em juvenis de Brycon cephalus. A taxa de crescimento específico (TCE) foi influenciada pela relação $\mathrm{PB}: \mathrm{CH}$. O melhor índice foi obtido com a relação 1,24 (Tab. 2). Como o peso dos animais é considerado para cálculo dessa taxa de crescimento, o efeito foi semelhante ao ganho de peso. As taxas variam de acordo com o nutriente testado e a espécie. Maiores valores dessa taxa em relação a este estudo foram obtidos por Refstie et al. (2004) em Salmo salar, Okamoto et al. (2006) em Mugil platanus.

As relações $\mathrm{PB}: \mathrm{CHO}$ influenciaram o consumo de ração $(\mathrm{P} \geq 0,05)$. $\mathrm{O}$ maior consumo aparente de ração ocorreu no grupo alimentado com a relação PB:CHO de 0,84 (Tab. 2). O efeito da proteína ou do carboidrato sobre o consumo de ração tem sido descrito por vários autores (Izel et al., 2004; Okamoto et al., 2006; Moreira et al., 2008; Tan et al., 2009).

Os índices de rendimento de carcaça (RC) não foram influenciados pelas relações $\mathrm{PB}: \mathrm{CHO}$ testadas (Tab. 2). A variação do rendimento de carcaça depende de vários fatores, além dos nutrientes, a idade, o sexo e a espécie (Souza et al., 1999; Burkert et al., 2008; Crepaldi et al., 2008). Resultados superiores a este trabalho foram relatados por Souza et al. (1999), os quais trabalharam com bagre Clarias gariepinus e obtiveram valores de rendimento de carcaça entre 91,07 e 93,78\%. Pode ser que o RC não tenha sido influenciado pelas relações $\mathrm{PB}: \mathrm{CHO}$ devido ao tempo do experimento e à idade dos peixes neste experimento.

Estes dados de desempenho zootécnico obtido no híbrido, com as variações de proteína e carboidrato, podem estar relacionados às características anatomofisiologicas. Os processos digestivos, de absorção e metabólicos, influenciam a mucosa, a qual apresenta papel importante no aproveitamento dos nutrientes (Kuperman e Kuz'mina, 1994). No estudo realizado com o gênero Pseudoplatystoma, as concentrações de proteína na ração alteraram as atividades enzimáticas proteolíticas, aminolíticas e de lipídios, além de adaptação das microvilosidades intestinais (Lundstedt, 2003). Embora não tenham sido analisados neste estudo os aspectos da digestão e da morfologia, é provável que estes tenham apresentado alguma influência nas respostas de desempenho e, consequentemente, metabólicas.

Os parâmetros metabólicos do plasma, a glicemia, o colesterol e a proteína plasmática total foram alteradas pelas diferentes relações PB:CHO (Tab. 3). As maiores taxas glicêmicas encontradas foram nas relações $\mathrm{PB}: \mathrm{CHO}$ de 0,33 e 1,24, respectivamente. As concentrações do colesterol plasmático apresentaram efeito quadrático. As maiores concentrações foram nas relações PB:CHO de 0,33 e 1,24. Este resultado foi semelhante nas concentrações de proteínas plasmáticas totais. De acordo com Babin e Vernier (1989), as lipoproteínas plasmáticas formam um sistema dinâmico responsivo à dieta, variando tanto com a natureza quanto com as quantidades ingeridas. As respostas desses metabólitos no plasma são descritas por vários autores (Hemre et al., 2002; Lundstedt, 2003; Melo et al., 2006; Tan et al., 2009). Tais parâmetros são indicativos no entendimento das estratégias metabólicas para manter os processos normais de crescimento e sobrevivência. 
Tabela 3. Valores médios da glicemia (GLIC), taxa de colesterol (COL), concentração plasmática de proteínas totais (PTN totais) plasmáticas, glicogênio hepático e atividade enzimática da aspartato aminotransferase (AST) hepática de juvenis de híbridos de Pseudoplatystoma fasciatum (fêmea) versus Leiarius marmoratus (macho) submetidos a diferentes relações proteína:carboidrato, alimentados por 50 dias

\begin{tabular}{|c|c|c|c|c|c|c|}
\hline \multirow{2}{*}{$\begin{array}{c}\text { Parâmetros de } \\
\text { desempenho e } \\
\text { metabólitos }\end{array}$} & \multicolumn{4}{|c|}{ Tratamentos (Relações PB:CHO) } & \multirow{2}{*}{$\begin{array}{c}\mathrm{CV} \\
\%\end{array}$} & \multirow{2}{*}{ Equação de regressão } \\
\hline & 1,24 & 0,85 & 0,51 & 0,33 & & \\
\hline GLIC $\left(m g \cdot \mathrm{dL}^{-1}\right)$ & $71,91 \mathrm{~b}$ & $47,52 \mathrm{c}$ & $51,37 \mathrm{bc}$ & 104,89 a & 26,82 & $\begin{array}{c}\mathrm{y}=222,53 \mathrm{x}^{2}-376 \mathrm{x}+198,08 \mathrm{R}^{2}= \\
0,87\end{array}$ \\
\hline $\mathrm{COL}\left(\mathrm{mg} \cdot \mathrm{dL}^{-1}\right)$ & $270,88 \mathrm{a}$ & $149,14 \mathrm{~b}$ & $196,24 \mathrm{~b}$ & $260,64 \mathrm{a}$ & 22,66 & $\begin{array}{c}\mathrm{y}=690,6 \mathrm{x}^{2}-1033,2 \mathrm{x}+532,26 \mathrm{R}^{2} \\
=0,99\end{array}$ \\
\hline PTN totais $\left(\mathrm{mg} \cdot \mathrm{dL}^{-1}\right)$ & $3,63 \mathrm{a}$ & $2,96 \mathrm{bc}$ & $2,72 \mathrm{c}$ & $3,42 \mathrm{ab}$ & 15,89 & $\begin{array}{c}\mathrm{y}=3,3682 \mathrm{x}^{2}-4,8855 \mathrm{x}+4,5488 \mathrm{R}^{2} \\
=0,85\end{array}$ \\
\hline $\begin{array}{l}\text { Glicogênio }\left(\mu \text { mol. } g^{-1}\right) \\
\left.\text { AST (U.g }{ }^{-1} \text { prot }^{*}\right)\end{array}$ & $\begin{array}{c}4,87 \mathrm{c} \\
35,01 \mathrm{a} \\
\end{array}$ & $\begin{array}{l}11,90 \mathrm{~b} \\
7,29 \mathrm{~b}\end{array}$ & $\begin{array}{l}16,03 \mathrm{a} \\
9,90 \mathrm{~b}\end{array}$ & $\begin{array}{c}13,51 \mathrm{ab} \\
38,38 \mathrm{a}\end{array}$ & $\begin{array}{l}18,14 \\
28,96 \\
\end{array}$ & $\begin{array}{c}y=-10,691 x+19,382 R^{2}=0,77 \\
y=15,2 x^{2}-18 x+26,54 R^{2}=0,92\end{array}$ \\
\hline
\end{tabular}

Letras iguais na coluna indicam não haver diferença significativa pelo teste Tukey $(\mathrm{P} \leq 0,05)$, entre as relações proteína:carboidrato.

*Proteína.

Em relação às reservas energéticas, o glicogênio hepático apresentou declínio linear significativo (Tab. 3). Esse fato sugere que as reservas hepáticas de glicogênio talvez tenham sido utilizadas na manutenção e no aumento das concentrações da glicose plasmáticas. Resultado semelhante foi observado por Melo et al. (2006) em Rhamdia quelen. Já Moreira et al. (2008) não constataram estes efeitos das relações PB:CHO.

Os níveis de glicogênio no tecido hepático são adaptáveis à dieta (Hemre et al., 2002; Melo et al., 2006). Em estudo realizado por Suárez et al. (2002), os teores de glicogênio aumentam com dietas ricas em CHO para Angilla anguilla e Oncorhynchus mykis.

A atividade da enzima AST no tecido hepático apresentou efeito quadrático (Tab. 3). As maiores médias foram nas relações PB:CHO de 0,33 e 1,24 . O aumento da atividade dessa enzima está associado a processo de transaminação de aminoácidos para uso de energético e excreção de nitrogenados. Gaye-Siessegger et al. (2006) observaram em Oreochromis niloticus que o aumento da proteína nas dietas aumentou a atividade da aspartato aminotransferase e concluíram que os excessos de aminoácidos foram desaminados e oxidados no ciclo de Krebs ou convertidos em gordura e carboidratos. Melo et al. (2006) verificaram, no jundiá Rhamdia quelem, aumento na AST e ALT (alanina aminotransferase) com o aumento da proteína na dieta, sugerindo aumento do catabolismo proteico. Neste estudo, o aumento da atividade da AST parece estar envolvido na regulação da glicemia e das reserva hepáticas.

\section{CONCLUSÕES}

A relação proteína:carboidrato de 0,84 é indicada para melhor desempenho de juvenis do híbrido de $P$. fasciatum (fêmea) e $L$. marmoratus (macho). A relação PB:CHO de 0,84 melhora os índices de conversão alimentar aparente e as taxas de crescimento e de consumo de ração. As relações $\mathrm{PB}: \mathrm{CHO}$ testadas não alteraram os índices de rendimento de carcaça. As dietas com alta e baixa relação proteína:carboidrato promovem o uso de nutrientes para regular o metabolismo, por meio do glicogênio e da atividade da AST para obtenção de energia.

\section{REFERÊNCIAS}

ANDRADE, R.L.B.; WAGNER, R.L.; MAHL. I. et al. Custos de produção de tilápias (Oreochromis niloticus) em um modelo de propriedade da região oeste do Estado do Paraná, Brasil. Cienc. Rural., v.35, p.198-203, 2005.

BABIN, P.J.; VERNIER, J-M. Plasma lipoproteins in fish. J. Lipid Research., v.30, p.467, 1989.

BIDINOTTO, P.M.; MORAES, G.; SOUZA, R.H.S. Hepatic glycogen and glucose in girth tropical freshwater teleost fish: A procedure for field determinations of micro samples. Bol. Tec. CEPTA., v.10, p.53-60, 1997. 
BOTARO, D.; FURUYA,W.M.; SILVA, L.C.R. et al. Redução da proteína da dieta com base no conceito de proteína ideal para tilápias-do-nilo (Oreochromis niloticus) criadas em tanques-rede. Rev. Bras. Zootec., v.36, p.517-525, 2007.

BOYD, C. Water quality in ponds for aquaculture. London: Birmingham Publishing Co., 1990. 482p.

BOYD, C.E. Water Quality for Pond Aquaculture. Research and Development Series No. 43. International Center for Aquaculture and Aquatic Environments, Alabama Agricultural Experiment Station, Auburn University, Alabama. 1998.

BURKERT, D.; ANDRADE, R.D.; SIROL, R.N. et al. Rendimentos do processamento $\mathrm{e}$ composição química de filés de surubim cultivado em tanques-rede. Rev. Bras. Zootec., v.37, p.1137-1143, 2008.

BUTTLE, L.G.; UGLOW, R.F.; COWX, I.G. Effects of dietary protein on the nitrogen excretion and growth of the African catfish, (Clarias gariepinus). Aquatic. Living Resource, v.8, p.407-414, 1995.

CREPALDI, D.V.; TEIXEIRA, E.A.; FARIA, P.M. et al. Rendimento de carcaça em surubim (Pseudoplatystoma spp.) avaliado por ultra-som. Rev. Bras. Saúde Prod. Anim., v.9, p.813-824, 2008.

CRUZ-CASALLAS, N.E.; MARCIALES-CARO, L.J.; DIAZ-OLARTE, J.J.D. et al. Acondicionamiento a dieta seca de larvas de yaque (Leiarius marmoratus) obtenidas por reproducción artificial. Rev. Colomb. Cienc. Pec., v.21, p.455-522, 2008.

FARIA, P.M.C.; LUZ, R.K.; PRADO, S.A. et al. Produção do híbrido "cachadia" em diferentes densidades de estocagem em sistema de recirculação de água. Arq. Bras. Med. Vet. Zootec., v.63, p.1208-1214, 2011.

FERNÁNDEZ, F.; MIQUEL, A.G.; CÓRDOBA, M. et al. Effects of diets with distinct protein-tocarbohydrate ratios on nutrient digestibility, growth performance, body composition and liver intermediary enzyme activities in gilthead sea bream (Sparus aurata, L.) fingerlings. J. Exp. Mar. Biol. Ecol., v.347, p.1-10, 2007.
FRASCÁ-SCORVO, C.M.D.; BACCARIN, L. A.; VIDOTTI, R. et al. Influência do sistema de criação no rendimento de carcaça, sabor, odor e na composição centesimal do pintado, Pseudoplatystoma corruscans. In: AQUIMERCO, 8., 2004, Espírito Santo. Anais... Espírito Santo: AQUABIO. 2004. p.81. (Resumo)

FURUYA,W.M.; PEZZATO, L.E.; MIRANDA, E.C. et al. Digestibilidade aparente da energia e nutrientes do farelo de canola pela tilápia do Nilo (Oreochromis niloticus). Rev. Bras. Zootec.,v.30, p.611-616, 2001.

GAYE-SIESSEGGER, J.; FOCKEN, U.; BECKER, $\mathrm{K}$. Effect of dietary protein/carbohydrate ratio on activities of hepatic enzymes involved in the amino acid metabolism of Nile tilapia, Oreochromis niloticus (L.) Fish Phys. Bio., v.32, p.275-282, 2006.

HASHIMOTO, D.T. Caracterização citogenética e molecular de híbridos interespecíficos das espécies Piavuçu (Leporinus macrocephalus) e Piapara (Leporinus elongatus), utilizados na piscicultura brasileira. 2008. 164f. Dissertação (Mestrado em Ciências Biológicas) Universidade Estadual Paulista - Unesp, Botucatu, SP.

HEMRE, G.I.; MOMMSEN, T.P.; KROGDAHL, A. Carbohydrates in fish nutrition: effects on growth, glucose metabolism and hepatic enzymes. Aquac. Nutrit., v.8, p.175-194, 2002.

HUANG, C.M.; LIAO, J.C. Response to mass selection for growth rate in (Oreochromis niloticus). Aquaculture., v.85, p.199-205, 1999.

IZEL, A.C.U.; PEREIRA-FILHO, M.; MELO, L.A.S. et al. Avaliação de níveis proteicos para a nutrição de juvenis de matrinxã (Brycon cephalus). Acta Amaz., v.34, p.179-184, 2004.

KOSSOWSKI, C. Hibridación del bagre zamurito Calophysus macropterus (pisces, pimelodidae). Bioagro., v.13, p.71-77, 2001.

KUPERMAN, B.I.; KUZ'MINA, V.V. The structure of the intestinal epithelium in fish with differente types of feeding. J. Fish. Biol., v.44, p.181-193, 2004. 
LUNDSTEDT, L.M. Aspectos adaptativos dos processos digestivo e metabólico de juvenis de pintado (Pseudoplatystoma corruscans) arraçoados com diferentes níveis de proteína e energia. 2003. 140f. Tese (Doutorado em Ciências Biológicas)Universidade Federal de São Carlos-UFSCar, São Carlos, SP.

MATEO, F.J.; DELGADO, N.; LÓPEZ, H. Caracterización Morfométrica del Híbrido Yaque Pintado (Pseudoplatystoma fasciatum x Leiarius marmoratus) y sus Progenitores (Siluriformes: Pimelodidae). Rev. de la Fac. de Cienc. Veter., v.49, p.47-60, 2008.

MATEO, F.J.; ROJAS, H.L. Comparación Alométrica entre los Híbridos Yaque Pintado (Pseudoplatystoma fasciatum $\mathrm{x}$ Leiarius marmoratus) y Chorrosco (Pseudoplatystoma fasciatum $x$ Pimelodus blochi) (Siluriformes: Pimelodidae). Rev. de la Fac. de Cienc. Veter., v.46, p.87-97, 2005.

MELO, J.F.B.; LUNDSTEDT, L.M.; METON, I. et al. Effects of dietary of protein on nitrogenous metabolism of Rhamdia quelen (Teleostei: Pimelodidae). Comp. Bio. and Physiol., v.145, p.181-187, 2006.

MELO, J.F.B.; SEABRA, A.G.L.; SOUZA, S.A. et al. Substituição do farelo de milho pela farinha de manga no desempenho da tilápia-do-nilo. 2011. Arq. Bras. Med. Vet. Zootec., v.64, p.177$182,2012$.

MELO, J.F.B.; LUNDSTEDT, L.M.; MORAES, G.; INOUE, L.A.K.A. Effect of different concentrations of protein on the digestive system of juvenile silver catfish. Arq. Bras. Med. Vet. Zootec., v.64, p.450-457, 2012a.

MOREIRA, I.S.; PERES, H.; COUTO, A. et al. Temperature and carboidrate level effects on performance and metabolic utilisation of diets in European sea bass (Dicentrarchus labraxI) juveniles. Aquaculture., v.274, p.153-160, 2008.

OKAMOTO, M.H.; SAMPAIO, L.A.; MAÇADA, A.P. Efeito da temperatura sobre o crescimento e a sobrevivência de juvenis da tainha, (Mugil platanus) (GÜNTHER, 1880). Atlântica., v.28, p.61-66, 2006.
REFSTIE, S.; OLLI, J.J.; STANDAL, H. Feed intake, growth, and protein utilization by postsmolt Atlantic salmon (Salmo salar) in response to graded levels of fish protein hydrolysate in the diet. Aquaculture., v.239, p.331-349, 2004.

SILVEIRA, U.S.; LOGATO, P.V.R.; PONTES, E.C. Utilização e metabolismo dos carboidratos em peixes. Rev. Eletr. Nutritime., v.6, p.817-836, 2009.

STATISTICAL Analysis Sistem - SAS Institute Inc. SAS 9.1.3 (TS1M3) for windows microsoft. Cary: NC, SAS Institute, 2007.

SOUSA, A.D.L. Efeito dos sistemas de criação semi-intensivo (viveiro escavado) e intensivo (tanque-rede) no desenvolvimento produtivo do pintado, Pseudoplatystoma corruscans (spix \& agassiz, 1829) (siluriformes: pimelodidae). 2005. 20f. Dissertação (Mestrado em Aquicultura) Universidade do estado de São Paulo - UNESP, Jaboticabal, SP.

SOUZA, M.L.R.; LIMA, S.; FURUYA, W.M. et al. Estudo de carcaça do bagre africano (Clarias gariepinus) em diferentes categorias de peso. Acta Scientiarum, v.21, p.637-644, 1999.

SUÁREZ, M.D.; SANZ, A.; BAZOCO, J.; GARCÍA-GALLEGO, M. Metabolic effects of changes in the dietary protein:carbohydrate ratio in eel (Angilla anguilla) and trout (Oncorhynchus mykiss). Aquac. Intern., v.10, p.143-156, 2002.

TAN, Q.; WANG, F.; XIE, S. et al. Effect of high dietary starch levels on the growth performance, blood chemistry and body composition of gibel carp (Carassius auratus var. gibelio). Aquac. Res., v.40, p.1011-1018, 2009.

VIAPLANA-MARÍN, I.; FERNÁNDEZ-BORRÁS, J.; BLASCO, J. Effects of the protein/ carbohydrate ratio of extruded diets on protein synthesis, protein growth and body composition in juvenile brown trout (Salmo trutta). Aquac. Intern., v.14, p.337-353, 2006. 